\title{
Arsenic remediation of drinking water using iron-oxide coated coal bottom ash
}

\author{
Johanna L. Mathieu ${ }^{1,2}$, Ashok J. Gadgil ${ }^{2,3}$, Susan E.A. Addy ${ }^{2,3}$, Kristin Kowolik ${ }^{4}$ \\ ${ }^{1}$ Department of Mechanical Engineering \\ University of California, Berkeley \\ Berkeley, CA, USA \\ ${ }^{2}$ Lawrence Berkeley National Laboratory \\ Environmental Energy Technologies Division \\ Berkeley, CA, USA \\ ${ }^{3}$ Department of Civil and Environmental Engineering \\ University of California, Berkeley \\ Berkeley, CA, USA \\ ${ }^{4}$ Department of Chemistry \\ University of California, Davis \\ Davis, CA, USA
}

June 2010

This work was conducted at the University of California, Berkeley and Lawrence Berkeley National Laboratory under U.S. Department of Energy Contract No. DE-AC02-05CH11231. Funders include NCIIA, and the University of California, Berkeley's Blum Center for Developing Economies and Bears Breaking Boundaries Contest. 


\title{
Arsenic remediation of drinking water using iron-oxide coated coal bottom ash
}

\author{
JOHANNA L. MATHIEU ${ }^{1,2}$, ASHOK J. GADGIL ${ }^{2,3^{*}}$, SUSAN E.A. ADDY ${ }^{2,3}$, and \\ KRISTIN KOWOLIK ${ }^{4}$
}

${ }^{1}$ Department of Mechanical Engineering, University of California, Berkeley, CA, USA

${ }^{2}$ Lawrence Berkeley National Laboratory, Berkeley, CA, USA

${ }^{3}$ Department of Civil and Environmental Engineering, University of California, Berkeley, CA, USA

${ }^{4}$ Department of Chemistry, University of California, Davis, CA, USA

\begin{abstract}
We describe laboratory and field results of a novel arsenic removal adsorbent called 'Arsenic Removal Using Bottom Ash' (ARUBA). ARUBA is prepared by coating particles of coal bottom ash, a waste material from coal fired power plants, with iron (hydr)oxide. The coating process is

* Address correspondence to Ashok Gadgil, Lawrence Berkeley National Laboratory, 1

Cyclotron Rd MS 90R3058, Berkeley, CA 94720, USA; Phone: 510-486-4651, Fax: 510-4866658; Email: ajgadgil@lbl.gov.
\end{abstract}


simple and conducted at room temperature and atmospheric pressure. Material costs for ARUBA are estimated to be low ( $\sim \$ 0.08$ per $\mathrm{kg})$ and arsenic remediation with ARUBA has the potential to be affordable to resource-constrained communities. ARUBA is used for removing arsenic via a dispersal-and-removal process, and we envision that ARUBA would be used in community-scale water treatment centers. We show that ARUBA is able to reduce arsenic concentrations in contaminated Bangladesh groundwater to below the Bangladesh standard of $50 \mathrm{ppb}$. Using the Langmuir isotherm $\left(\mathrm{R}^{2}=0.77\right)$ ARUBA's adsorption capacity in treating real groundwater is $2.6 \times 10^{-6} \mathrm{~mol} / \mathrm{g}(0.20 \mathrm{mg} / \mathrm{g}$ ). Time-to- $90 \%$ (defined as the time interval for ARUBA to remove $90 \%$ of the total amount of arsenic that is removed at equilibrium) is less than one hour. Reaction rates (pseudo-second-order kinetic model, $\mathrm{R}^{2} \geq 0.99$ ) increase from $2.4 \times 10^{5}$ to $7.2 \times 10^{5} \mathrm{~g} \mathrm{~mol}^{-1}$ $\min ^{-1}$ as the groundwater arsenic concentration decreases from 560 to $170 \mathrm{ppb}$. We show that ARUBA's arsenic adsorption density (AAD), defined as the milligrams of arsenic removed at equilibrium per gram of ARUBA added, is linearly dependent on the initial arsenic concentration of the groundwater sample, for initial arsenic concentrations of up to $1600 \mathrm{ppb}$ and an ARUBA dose of $4.0 \mathrm{~g} / \mathrm{L}$. This makes it easy to determine the amount of ARUBA required to treat a groundwater source when its arsenic concentration is known and less than $1600 \mathrm{ppb}$. Storing contaminated groundwater for two to three days before treatment is seen to significantly increase ARUBA's AAD. ARUBA can be separated from treated water by coagulation and clarification, which is expected to be less expensive than filtration of micron-scale particles, further contributing to the affordability of a community-scale water treatment center.

Keywords: arsenic, Bangladesh, coal bottom ash, drinking water, water contaminants, water treatment 


\section{INTRODUCTION}

Naturally occurring arsenic in drinking water threatens the health and lives of people in many countries including Argentina, Chile, Mexico, Ghana, Hungary, Greece, Bangladesh, Vietnam, and India. ${ }^{[1]}$ In 2008, in Bangladesh alone, about 20 million people were drinking water contaminated with high ( $>50 \mathrm{ppb}$ ) levels of arsenic. ${ }^{[2]}$ Prior to 1970 , most rural Bangladeshis had access only to surface waters that were commonly contaminated with pathogens, leading to prevalence of water-borne diseases. To address this problem, millions of shallow tube wells were drilled into the Ganges aquifers and fitted with hand pumps to provide access to pathogen-free groundwater. It was unknown at the time that the much of the groundwater in the Ganges Delta contains high levels of naturally occurring arsenic. Arsenic concentrations in groundwater in many areas of Bangladesh are up to 100 times the $10 \mathrm{ppb}$ limit recommended by the World Health Organization (WHO) and United States Environmental Protection Agency (US EPA). ${ }^{[3]}$ The Bangladesh standard for safe drinking water is $50 \mathrm{ppb}$.

Chronic exposure to arsenic contaminated water leads to serious health problems including skin lesions on the hands and feet; cancers of the lungs, bladder, kidney, and skin; neurological effects; hypertension and cardiovascular disease; pulmonary disease; peripheral vascular disease; and diabetes mellitus. ${ }^{[4]}$ In 2008, 40,000 people in Bangladesh were showing signs of arsenic poisoning. ${ }^{[2]}$ Where groundwater arsenic concentrations are greater than $500 \mathrm{ppb}$, as it is in many villages in southern Bangladesh, one in ten adults is at risk of dying from arsenic-related cancers. ${ }^{[4]}$ 
Many approaches have been investigated for removing arsenic from drinking water. Reviews of techniques to remove arsenic from water are presented by Ahmed ${ }^{[5]}, \mathrm{Ng}$ et al. $^{[6]}$, and Mohan and Pitman ${ }^{[7]}$. Successful arsenic removal techniques related to the work presented in this paper include removal with iron-oxide coated sand ${ }^{[8]}$ or iron-impregnated sand ${ }^{[9]}$, direct adsorption on metallic (zero-valent) iron ${ }^{[10-12]}$, iron-chelated resins ${ }^{[13]}, \mathrm{Fe}^{2+}$-treated activated carbon ${ }^{[14]}$, magnetite nanocyrstals ${ }^{[15]}$, polymer beads coated with iron oxides ${ }^{[16]}$, granulated ferric hydroxide $(\mathrm{GFH})^{[17-18]}$, and composite iron matrix ${ }^{[19]}$. Despite numerous methods for removing arsenic from drinking water, arsenic remediation is not widespread in Bangladesh, in part, because many of the existing techniques are cumbersome and/or not affordable to rural populations.

In this paper, we present performance results and analysis regarding a novel method for removing arsenic from contaminated groundwater that has the potential to be affordable to rural Bangladeshis. This method is based on coating coal bottom ash with ferric (hydr)oxide to create an arsenic removal media called 'Arsenic Removal Using Bottom Ash,' or ARUBA. Early work on ARUBA was published in Gadgil et al. ${ }^{[20]}$. ARUBA is novel and of interest for the following reasons:

(1) It is based on using coal bottom ash as a substrate. Coal bottom ash is a finely powdered, sterile waste material that is found at the bottom of coal-fired boilers after combustible matter has been burned off. Since bottom ash is waste, it is inexpensive-about $\$ 4$ per tonne (i.e. 1000 $\mathrm{kg}$ ) from Indian coal-fired power plants (personal communication: Girish Champhekar, 2008). Unlike brick, bottom ash does not require crushing before it is coated with rust, thus using less 
mechanical energy than is required to prepare brick powder. This helps keep the cost low.

(2) Bottom ash has a much larger surface area to volume ratio than most substrates. For example, the surface area to volume ratio of coal ash is 200 times greater than that of sand (assuming spherical sand particles with $1 \mathrm{~mm}$ diameters and spherical coal ash particles with $5 \mu \mathrm{m}$ diameters).

(3) The method of coating coal bottom ash with ferric (hydr)oxide is inexpensive, novel, and low-energy. ARUBA preparation uses readily-available, inexpensive chemicals and each step of the preparation process (including drying) is conducted at room temperature and atmospheric pressure. Methods for coating substrates with rust usually involve high temperature baking/drying. Ramakrishna et al. ${ }^{[21]}$ list 13 methods for coating sand with iron oxides. All but two of the methods require high temperature $\left(\geq 100^{\circ} \mathrm{C}\right)$ baking/drying. Even in the remaining two methods ${ }^{[22-23]}$, a sand plus ferric nitrate solution mixture is dried for 96 hours at $\sim 50^{\circ} \mathrm{C}$, which requires significant thermal energy.

ARUBA particles are very small $(1-10 \mu \mathrm{m})$; therefore, we do not envision that ARUBA would be used in packed-bed filters since very large pressure drops will be required to obtain reasonable flow rates. Instead, we envision that ARUBA would be used in a dispersal-andremoval process. Therefore, all of the water treatment experiments described in this paper employ a dispersal-and-removal process, rather than a packed-bed filter.

The rest of this paper is organized as follows: We begin with a description of the materials and methods used in the laboratory and fieldwork. We then describe ARUBA process chemistry, surface morphology, and particle size. We define ARUBA's Arsenic Adsorption Density (AAD) 
as the milligrams of arsenic removed at equilibrium per gram of ARUBA added, and we present an analysis of ARUBA's AAD in removing $\mathrm{As}(\mathrm{V})$ from aqueous arsenate solution in the laboratory. Next, we present the results of experiments to quantify ARUBA's ability to remove arsenic from real groundwater. We discuss our key findings: (1) ARUBA is able to lower arsenic concentrations in groundwater to below the Bangladesh standard of $50 \mathrm{ppb}$; (2) it takes less than one hour for ARUBA to remove $90 \%$ of the arsenic removed at equilibrium; (3) experimental data fit the pseudo-second-order kinetics model the best; (4) ARUBA's AAD improves with pretreatment water storage; (5) ARUBA's AAD is linearly related to the groundwater's initial arsenic concentration (up to $1600 \mathrm{ppb}$ ) making it easy to determine the amount of ARUBA required to treat a groundwater source if its arsenic concentration is known; (6) experimental data fit three standard isotherm models more-or-less similarly; (7) coagulation/clarification is capable of removing ARUBA from treated water nearly as effectively as filtration; (8) ARUBA is

able to lower manganese concentration in groundwater; (9) ARUBA does not contaminate water with other toxic metals; and (10) spent ARUBA passes US EPA tests for disposal in municipal landfills. Finally, we discuss a possible community-scale implementation model and cost estimates.

\section{MATERIALS AND METHODS}

General materials and methods are presented in this section. Specific methods are presented in the Results section, as appropriate.

\section{Analytical Methods}




\section{Imaging}

Scanning electron microscopy (SEM) was used to image uncoated bottom ash and ARUBA. Samples were coated in metallic gold and imaged using a Hitachi SE/N 4300 scanning electron microscope at Lawrence Berkeley National Laboratory. An accelerating voltage of $20 \mathrm{kV}$ was used to obtain images at 5,000x magnification.

\section{Arsenic measurements}

Most water samples were acidified with nitric acid and analyzed for total arsenic within two months of collection using Inductively Coupled Plasma - Mass Spectrometry (ICP-MS), via US EPA Method 6020, at Curtis and Tompkins Ltd. (Berkeley, CA, USA), a commercial laboratory certified with the US EPA. A small number of water samples (un-acidified) were analyzed for total arsenic within two weeks of collection by GF-AAS (Graphite Furnace - Atomic Adsorption Spectroscopy) at the Environmental Engineering Laboratory in the Department of Civil Engineering at the Bangladesh University of Engineering and Technology (BUET) (Dhaka, Bangladesh). Reported error for both measurement techniques is $\pm 10 \%$ (minimum error of 2 ppb). When both ICP-MS and GF-AAS measurements were available we present ICP-MS results.

Arsenic QuickTest (Industrial Test Systems Inc., Rock Hill, SC, USA) was used in the field to estimate arsenic concentrations in water samples, before the samples were sent for more accurate 
ICP-MS or GF-AAS analysis. QuickTest results were used for screening decisions only, and therefore quantitative results are not reported in this paper.

As(III) was measured with speciation cartridges (MetalSoft Center, Highland Park, NJ, USA).

The cartridges consist of a sand filter containing an aluminosilicate adsorbent, which selectively adsorbs $\mathrm{As}(\mathrm{V})$ and not $\mathrm{As}(\mathrm{III})$ between $\mathrm{pH} 4$ and 9. Arsenic-contaminated water is forced through the cartridge with a plastic syringe. $\mathrm{As}(\mathrm{V})$ adsorbs to the aluminosilicate adsorbent, while As(III) passes through the cartridge. Total As(III) is determined by measuring the total arsenic concentration of the filtrate. ${ }^{1}$

\section{Measurements of other elements}

To quantify manganese removal with ARUBA, the manganese content of several water samples (un-acidified) was analyzed with GF-AAS at BUET.

To determine the effect of ARUBA on other parameters of drinking water quality, a sample of ARUBA-treated water (acidified with nitric acid) was analyzed for Resource Conservation and

\footnotetext{
${ }^{1}$ Water samples were not filtered before passing through the speciation cartridge, though prefiltering was recommended by the manufacturer. Therefore, our As(III) measurements could be biased if $\mathrm{As}(\mathrm{V})$, adsorbed to sub-micron naturally-occurring iron precipitates, passed through the speciation cartridges. We expect this bias to be small because initial As(III) concentrations were measured within 10 minutes of collection. It is unlikely that a significant amount of iron precipitates had formed by this time. Subsequent As(III) concentrations were measured many hours after sample collection ( $>12$ hours) and it is likely that by this time the iron precipitates were large enough that they, together with the arsenic adsorbed to them, were caught in the speciation cartridge filter (note the amount of arsenic that was removed by filtration in Figure 6). Therefore, the As(III) results presented in this paper are a good proxy for the total amount of aqueous As(III) in the water sample.
} 
Recovery Act (RCRA) listed metals (arsenic, barium, cadmium, chromium, lead, mercury, selenium, and silver), in addition to several other metals found in bottom ash (beryllium, copper, manganese, molybdenum, and nickel) with ICP-MS at Curtis and Tompkins Ltd.

\section{Leachate preparation and analysis}

To determine if toxic metals leach from spent ARUBA, a Toxicity Characteristic Leaching Procedure (TCLP) was performed on spent media using US EPA Method 1311. The leachate was digested and concentrations of RCRA listed metals and several other metals found in bottom ash (beryllium, copper, manganese, molybdenum, and nickel) were measured with Inductively Coupled Plasma - Atomic Emission Spectroscopy (ICP-AES) using US EPA Method 7470 for mercury, and US EPA Methods 3010A and 6010B for all other metals. Reported error for ICPAES is $\pm 10 \%$.

\section{ARUBA Preparation Protocol}

ARUBA preparation is a simple process illustrated in Figure 1. To make approximately $100 \mathrm{~g}$ of ARUBA, $100 \mathrm{~g}$ of bottom ash (in this case, obtained from a coal fired power plant in Eklahare, Nasik, Maharashtra, India) is added to $670 \mathrm{~mL}$ of $1.72 \mathrm{M} \mathrm{FeSO}_{4}$ and stirred for one hour. After 15 minutes of settling, the mixture is decanted. Next, $100 \mathrm{~mL}$ of $0.5 \mathrm{M} \mathrm{NaOH}$ solution is added and stirred for five minutes. Again, the mixture is left to settle for 15 minutes and then decanted. The remaining mixture is spread evenly onto a large baking dish and air-dried overnight in a fume hood at room temperature, allowing for oxidation of the ferrous coating. The following 
day, the media is collected and rinsed with successive aliquots $(\sim 500 \mathrm{~mL})$ of de-ionized water, decanting between each rinse, until the $\mathrm{pH}$ of the rinse water drops below 8 . The media is again spread onto a baking dish and dried overnight in a fume hood. On the third day the dry media is collected, tested, and stored.

\section{Arsenic Adsorption Density Tests}

$\mathrm{AAD}$ is defined as the milligrams of arsenic removed from solution at equilibrium per gram of ARUBA added, for given initial conditions (e.g., initial arsenic concentration, ARUBA dose, temperature, etc.). Arsenic adsorption capacity is defined as the maximum AAD. It can be determined by measuring the $\mathrm{AAD}$ of water samples with a broad range of initial conditions. It can also be predicted by fitting AAD data to adsorption isotherm models. In this paper, we take the latter approach. AAD characterizes the mass removal efficiency of ARUBA and is particularly relevant to designers and operators of arsenic removal systems who need to estimate the amount of ARUBA required (in a dispersal-and-removal process) to remove arsenic from contaminated groundwater, when its initial conditions are known. Later in this paper we show a worked example using AAD.

\section{Laboratory protocol}

In the laboratory, an ARUBA batch's AAD is determined by adding ARUBA to aqueous arsenate solution (generally, $0.50 \mathrm{~g}$ ARUBA per $250 \mathrm{~mL}$ solution $(2.0 \mathrm{~g} / \mathrm{L})$ ) and stirring, using a magnetic stir plate, for one hour. Aqueous arsenate solutions were prepared from 
$\mathrm{Na}_{2} \mathrm{HAsO}_{4} \cdot \mathrm{H}_{2} \mathrm{O}$ (Sigma) fully dissolved in de-ionized water ( $\mathrm{pH}$ 6.4-8.4). After stirring, the ARUBA-arsenate mixture is left to settle for 15 minutes and then filtered through Whatman Grade Number 40 Quantitative filter paper (particle retention of $8 \mu \mathrm{m}$ ) with a vacuum pump. The filtered water is tested for total arsenic concentration. Two AAD tests are always performed sideby-side and results are averaged for accuracy. For laboratory experiments reported in this paper, post-treatment $\mathrm{pHs}$ were 6.5-7.8.

\section{Field protocol}

For the purpose of this paper, we define field tests as those that were conducted on-site in Bangladesh or Cambodia using local groundwater. Field tests were conducted close to the point of collection so that water had not significantly aged before treatment with ARUBA. In the field, ARUBA's AAD was determined using a modified protocol due to equipment limitations. Specifically, ARUBA is added to arsenic contaminated groundwater (generally, 1.0 or $2.0 \mathrm{~g}$ ARUBA per $250 \mathrm{~mL}$ water $(4.0$ or $8.0 \mathrm{~g} / \mathrm{L}))$, in a $250 \mathrm{~mL}$ nominal bottle. The bottle is shaken vigorously for 30 seconds and then set down. Every 30 seconds for a total of 30 minutes the bottle is flipped to prevent ARUBA particles from settling. After 30 minutes the solution is filtered through Whatman Grade Number 1 filter paper (particle retention of $11 \mu \mathrm{m}$ ) using a plastic funnel positioned over a clean $250 \mathrm{~mL}$ bottle. The filtered water is sampled and tested for total arsenic. Again, two AAD tests are always performed side-by-side and results are averaged for accuracy.

\section{Computation of AAD}


To calculate ARUBA's AAD (mg/g), the final (post-treatment) total arsenic concentration (ppb) is subtracted from the initial (pre-treatment) total arsenic concentration (ppb) and divided by the dose of ARUBA (mg/L), as in Equation 1.

$$
\mathrm{AAD}=\left([\mathrm{As}]_{\text {initial }}-[\mathrm{As}]_{\text {final }}\right) /[\text { ARUBA }]
$$

\section{Comparison of lab and field protocols}

We determined that, after adding ARUBA to aqueous arsenate solution and continuously stirring, decline in the $\mathrm{As}(\mathrm{V})$ concentration stops (for practical purposes) within 30 minutes. We also verified that, in treating aqueous arsenate solution, $\mathrm{AAD}$ values determined using the field protocol (30 minute contact time) and the laboratory protocol (75 minute contact time) were consistent. However, by periodically extracting water samples from groundwater that was being treated with ARUBA, we discovered that arsenic in Bangladesh groundwater is slower to bind to ARUBA than $\operatorname{As}(V)$ in aqueous arsenate solution. Specifically, treatment of Bangladesh groundwater is not complete after 30 minutes (see Table 4 and Fig. 5). Consequently, the AAD values that were determined from Bangladesh groundwater samples and are reported in this paper are underestimates.

\section{Groundwater Sample Collection}

Groundwater samples were collected from tube wells in Bangladesh and Cambodia if onsite 
Arsenic QuickTest measurements showed arsenic concentrations greater than $50 \mathrm{ppb}$. Each tube well was pumped for five minutes before sample collection to minimize biological contamination and help flush oxygenated water out of the tube well column. Samples were stored in tightly sealed 1-1.5 liter PETE or HDPE plastic bottles. The time between water collection and the subsequent test/experiment was noted and reported as the 'Water Storage Duration.' Precipitates (likely to be iron complexes) were visible in the stored water approximately 30 minutes after collection. Water samples were not pre-filtered before experiments because we do not expect contaminated groundwater to be pre-filtered in implementation-scale ARUBA-based water treatment centers.

Eleven Bangladesh tube well water samples (details in Table 1) were treated with ARUBA to determine its ability to remove arsenic from Bangladesh groundwater. Higher ARUBA dosages were used in the field than in the lab in anticipation of lower AADs in Bangladesh groundwater than in aqueous arsenate solutions. Generally $1.0 \mathrm{~g}$ of ARUBA per $250 \mathrm{~mL}$ water $(4.0 \mathrm{~g} / \mathrm{L})$ was used. If $1.0 \mathrm{~g}$ did not reduce the arsenic concentration to less than $50 \mathrm{ppb}$, the test was repeated with $2.0 \mathrm{~g}$ of ARUBA per $250 \mathrm{~mL}$ water $(8.0 \mathrm{~g} / \mathrm{L})$. The amount of ARUBA used per water sample is reported as 'Dosage' in Table 1. The dosages were chosen to illustrate proof of concept, and are not optimized.

Ten $\mathrm{mL}$ samples for ICP-MS/GF-AAS analysis of initial groundwater arsenic concentration were collected either from the sample bottles before performing the first AAD test/experiment on that water sample (for samples JH1-3, AV1-3) or directly from the wellhead (for samples SO1-2, SR1-3). Precipitates were visible in the sample bottles before the $10 \mathrm{~mL}$ samples were collected, 
and therefore arsenic concentrations measured from the $10 \mathrm{~mL}$ samples collected from the sample bottles are expected to underestimate the actual arsenic concentration in the tube well source. Ten $\mathrm{mL}$ samples collected directly from the wellhead more accurately estimate the arsenic content of the tube well source. Samples were not filtered before ICP-MS/GF-AAS analysis.

Water samples collected for other experiments presented in this paper are listed in Table 2; we indicate in the last column the experiment for which the water sample was used. For Table 2, initial arsenic concentration was measured in samples taken directly from the wellhead.

For brevity, further details about each water sample that underwent AAD tests (results presented in Figure 7) are not included here. Full details appear in Mathieu ${ }^{[24]}$.

\section{RESULTS AND DISCUSSION}

\section{Process Chemistry}

The exact reactions governing ARUBA preparation are still unknown. A sketch of possible reactions is outlined below, using $\mathrm{Fe}(\mathrm{OH})_{3}$ to represent any of the possible hydrated ferric hydroxides or oxyhydroxides that may be formed. 
1. Ash is soaked in $\mathrm{FeSO}_{4}$ solution, depositing hydrated $\mathrm{Fe}(\mathrm{II})$ on the ash surface. The unknown extent of hydration is indicated by $\alpha$, and Ash $\mathrm{Fe}\left(\mathrm{H}_{2} \mathrm{O}\right)^{2+}{ }_{\alpha, s}$ represents the hydrated ferrous ion on the ash surface.

$\mathrm{Ash}+\mathrm{Fe}^{2+}+\alpha \mathrm{H}_{2} \mathrm{O} \rightarrow \mathrm{Ash} \cdot \mathrm{Fe}\left(\mathrm{H}_{2} \mathrm{O}\right)^{2+}{ }_{\alpha, \mathrm{s}}$

2. Ash is soaked in $\mathrm{NaOH}$ and $\mathrm{OH}^{-}$displaces water ligands to produce ferrous hydroxide on the ash surface.

$\mathrm{Ash} \bullet \mathrm{Fe}\left(\mathrm{H}_{2} \mathrm{O}\right)^{2+}{ }_{\alpha, \mathrm{s}}+2 \mathrm{OH}^{-} \rightarrow \mathrm{Ash} \bullet \mathrm{Fe}(\mathrm{OH})_{2, \mathrm{~s}}+\alpha \mathrm{H}_{2} \mathrm{O}$

3. During the drying process, exposure to air oxidizes the ferrous hydroxide to ferric hydroxide on the ash surface.

Ash $2 \mathrm{Fe}(\mathrm{OH})_{2, \mathrm{~s}}+1 / 2 \mathrm{O}_{2}+\mathrm{H}_{2} \mathrm{O} \rightarrow \operatorname{Ash} \bullet 2 \mathrm{Fe}(\mathrm{OH})_{3, \mathrm{~s}}$

Subsequent reactions governing arsenic removal with ARUBA are complex and not yet well understood. They could include any of the numerous possible reactions between arsenic and ferric oxides, hydroxides, and oxyhydroxides in the ARUBA coating.

\section{Surface Morphology}

X-ray fluorescence analysis indicates that the primary components of bottom ash are oxides and complexes of silicon, calcium, iron, aluminum, and magnesium. Under SEM, the ash particles appear to be mostly spherical with smooth almost glass-like surfaces (Fig. 2). This surface morphology is consistent with the ash being heated to near its melting point during the 
combustion process. SEM images of particles of ARUBA exhibit a ferric (hydr)oxide coating (Fig. 3), but an insignificant change in particle diameter.

\section{Particle Size}

Analysis of SEM images indicates that ARUBA particles are approximately 1 to $10 \mu \mathrm{m}$ in diameter. Particle size was also indirectly assessed by conducting AAD tests (laboratory protocol) with filter paper of different nominal pore sizes. A significant increase in the breakthrough arsenic concentration began to occur with pore sizes larger than $2.5 \mu \mathrm{m}$, indicating that the bulk of ARUBA particles are greater than $\sim 2.5 \mu \mathrm{m}$.

The minimum diameter of coal bottom ash (and therefore, ARUBA) is approximately $1 \mu \mathrm{m}$ because smaller ash particles become fly ash. A maximum ARUBA diameter size could be set through a suitable particle size separation process, such as aerodynamic separation.

\section{Removal of Arsenic from Aqueous Arsenate Solution}

The AAD of different batches of ARUBA is found to vary slightly depending on variations in the quality of the bottom ash and the preparation process. Variation in bottom ash reflects variation in coal; no further data were available for the source of the coal.

To understand the variability of ARUBA's AAD, we performed AAD tests (see 'Laboratory protocol' in Methods) on ten ARUBA batches using 2000 ppb aqueous arsenate solution and 
$2.0 \mathrm{~g} / \mathrm{L}$ of ARUBA. The mean pre-treatment arsenic concentration was $2000 \pm 100$ and the mean post-treatment arsenic concentration was $39 \pm 53 \mathrm{ppb}$, where the errors are the standard deviations of the measured values. The mean AAD was found to be $0.96 \pm 0.04 \mathrm{mg} / \mathrm{g}$, where the error is the standard deviation of the computed AAD values.

Two-year-old ARUBA (stored under ambient room conditions), tested using 2000 ppb aqueous arsenate solution and $2.0 \mathrm{~g} / \mathrm{L}$ of ARUBA, exhibited an AAD consistent with the mean, indicating no degradation in arsenic removal ability with media age (up to two years).

We tested spent ARUBA (i.e. ARUBA that has already been used to treat water) to determine if it is capable of removing more arsenic. Of the ten ARUBA batches that underwent the AAD tests described above, seven 'passed' meaning they were able to lower the aqueous arsenic concentration from $\sim 2000 \mathrm{ppb}$ to less than $50 \mathrm{ppb}$ with $2.0 \mathrm{~g} / \mathrm{L}$ of ARUBA. For these seven $\mathrm{AAD}$ tests the mean post-treatment arsenic concentration was $10 \pm 3 \mathrm{ppb}$ and the mean $\mathrm{AAD}$ was $0.96 \pm 0.03$. Spent ARUBA from each of these seven batches was dried and used in subsequent AAD tests, using $1900 \mathrm{ppb}$ aqueous arsenate solution and $2.0 \mathrm{~g} / \mathrm{L}$ of spent ARUBA. The mean post-treatment arsenic concentration was $37 \pm 15 \mathrm{ppb}$ and the mean AAD was found to be $0.93 \pm 0.05 \mathrm{mg} / \mathrm{g}$. The AAD of spent ARUBA (that has passed its first AAD test) is slightly lower than, though consistent with (i.e. within error bounds), the AAD of fresh ARUBA. This result suggests that fresh ARUBA capable of reducing groundwater arsenic concentrations to below $50 \mathrm{ppb}$ can be recovered as spent sludge, dried, and used again to substantially lower arsenic concentrations in more groundwater. 
Diamadopoulos et al. ${ }^{[25]}$ showed that high concentrations of aqueous As(V) $(50,000 \mathrm{ppb})$ could be lowered using coal fly ash without an iron coating. Therefore, we sought to quantify the value-added by coating bottom ash particles with ferric (hydr)oxide. We performed AAD tests using $\sim 1300 \mathrm{ppb}$ aqueous arsenate solution and $2.0 \mathrm{~g} / \mathrm{L}$ of either uncoated ash or ARUBA (results in Table 3). Uncoated bottom ash was unable to remove significant amounts of arsenic from aqueous arsenate solution.

\section{Removal of Arsenic from Real Groundwater Samples}

Groundwater samples were collected from a total of eleven different tube wells in four different upazilas (sub-districts) of Bangladesh and treated with ARUBA (see Methods for specifics of location, dosage, and water storage duration). Figure 4 shows the initial and post-treatment arsenic concentrations of the Bangladesh groundwater. In all cases, an ARUBA dose less than or equal to $8.0 \mathrm{~g} / \mathrm{L}$ is capable of reducing arsenic concentrations to below $50 \mathrm{ppb}$ (when the water is stored up to 77 hours). These results demonstrate the ability of ARUBA to reduce arsenic to less than $50 \mathrm{ppb}$ in real Bangladesh groundwater, but do not imply that $8.0 \mathrm{~g} / \mathrm{L}$ ARUBA is the minimum dosage required to do so- the minimum ARUBA dosage required is expected to be much lower with optimization. Note that we benchmark arsenic concentrations against the Bangladesh standard of $50 \mathrm{ppb}$. This benchmark was chosen for the purpose of characterizing the media. Arsenic removal to below the WHO guideline of $10 \mathrm{ppb}$ is achievable by adding higher doses of ARUBA.

\section{Time-to-90\%}


We define 'time-to- $90 \%$ ' as time interval for ARUBA to remove $90 \%$ of the total amount of arsenic that is removed at equilibrium (therefore, time-to- $90 \%$ is less than the time-toequilibrium). This parameter is relevant to designers of arsenic removal systems who need to determine how long it takes ARUBA to remove arsenic from water. To determine ARUBA's time-to-90\%, four water samples (SO3, SO4, SR7, and SR8) were treated with an ARUBA dose of $4.0 \mathrm{~g} / \mathrm{L}$. During the treatment period, water samples were periodically extracted from the treatment containers using plastic syringes, filtered, and stored for subsequent arsenic analysis. Figure 5 shows the decrease in arsenic concentration over time in groundwater samples during treatment with ARUBA. Table 4 shows the time-to- $90 \%$ for each of the four water samples. In all cases, time-to- $90 \%$ is less than one hour. Time-to- $90 \%$ seems to vary with initial/final arsenic concentration; however, more research is needed to quantify this relationship.

\section{Arsenic removal kinetics}

Data from each of the four time-to- $90 \%$ experiments were fit to three standard kinetics models (first-order, pseudo-second order, and intraparticle diffusion) ${ }^{[26]}$ to predict ARUBA's adsorption kinetics. Goodness-of-fit ( $\mathrm{R}^{2}$ values) for each model and each water sample are presented in Table 5. In all cases, the pseudo-second-order kinetic model is the best fit $\left(\mathrm{R}^{2} \geq 0.99\right)$. Table 5 also displays parameters for each model and each water sample. If we assume that the temperature for each experiment is consistent (the temperatures were in a narrow range: 26 to 31 ${ }^{\circ} \mathrm{C}$ ), we can compare reaction rates between the water samples. For the pseudo-second-order 
model, reaction rates increase from $2.4 \times 10^{5}$ to $7.2 \times 10^{5} \mathrm{~g} \mathrm{~mol}^{-1} \mathrm{~min}^{-1}$ as the groundwater arsenic concentration decreases from 560 to $170 \mathrm{ppb}$.

\section{Effects of water storage duration}

Pre-treatment storage of groundwater affects ARUBA's AAD. To quantify this effect, groundwater was collected and stored in uncapped bottles (open to the atmosphere) before treatment. The groundwater was not stirred during storage. At each interval we (1) measured the As(III) concentration of the stored water using arsenic speciation cartridges (see Methods), (2) filtered the water and took a sample (labeled 'Post-Filtration [As]' in Figure 6), and (3) treated the unfiltered water with ARUBA and took a sample (labeled 'Post-Treatment [As]' in Figure 6). Filtering allowed us to quantify arsenic removal due to natural precipitates in the groundwater.

Results for two samples, SR2 and SR3, are presented in Figures 6a and 6b, respectively. For SR2, pre-treatment pHs ranged from 7.1 to 8.2 and post-treatment $\mathrm{pHs}$ ranged from 7.4 to 7.9. For SR3, pre-treatment $\mathrm{pHs}$ ranged from 7.2 to 8.2 and post-treatment $\mathrm{pHs}$ ranged from 7.2 to 8.1. For each sample, the initial arsenic concentration and the post-filtration arsenic concentrations at zero hours are the same, within measurement error. This is not surprising as there were no visible precipitates in the water immediately after water collection. In both Figure 6a and $6 \mathrm{~b}$, post-filtration arsenic concentrations decrease modestly in the first 48 hours and then remain unchanged as water storage duration increases, indicating that natural precipitation can remove a small fraction of the arsenic. Post-treatment arsenic concentrations start low and decline to $<50 \mathrm{ppb}$ with increasing storage duration. For these samples, the nominal dose of 
ARUBA ( $4.0 \mathrm{~g} / \mathrm{L})$ removes much more arsenic than natural precipitation does, for water storage durations of 0-168 hours. With increasing storage duration (up to 48 hours) the same dose of ARUBA, working in combination with natural precipitation, removes increasingly more arsenic. Possible reasons for this include the decrease in the As(III) concentration over time, as seen in Figure 6 and/or adsorption of competing ions (e.g., phosphate and silicate) on naturallyoccurring iron precipitates.

\section{AAD in Bangladesh and Cambodia}

To determine ARUBA's AAD for groundwater from Bangladesh and Cambodia as a function of initial arsenic concentration, AAD tests were performed on a total of 27 water samples. Specifically, 20 water samples from four sub-districts in Bangladesh and seven water samples from three sub-districts in Cambodia (Leuk Daek in Kaoh Thum District, Dei Edith and Preak Aeng in Kien Svey District) were treated with an ARUBA dose of $4.0 \mathrm{~g} / \mathrm{L}$. Figure 7 shows AAD increases with increasing initial arsenic concentration for all samples and the relationship remains linear in the range explored (0-1600 ppb). Regression lines (forced to intersect the origin) were fitted separately for Bangladesh samples treated within one day of collection ( $\mathrm{n}=16$ ), Bangladesh samples treated more than two days after collection $(\mathrm{n}=4)$, and Cambodia samples treated less than one day after collection $(\mathrm{n}=7)$. Interestingly, the two regression lines for samples stored less than one day are consistent despite the geographic distance between Bangladesh and Cambodia. The regression line for water stored more than two days shows a steeper slope indicating that water storage improves AADs, as also seen in the previous section. 
Note that ARUBA's AAD in treating water from Bangladesh/Cambodia is lower than its AAD in treating aqueous arsenate solution. This is true even if ARUBA's AAD regression lines are projected out to initial arsenic concentrations of $2000 \mathrm{ppb}$ (though note that the linear relation we have observed may not hold out to $2000 \mathrm{ppb}$ ). We believe there are two likely reasons why these results differ:

1. Bangladesh groundwater has high concentrations of As(III), which ARUBA, like most ironbased adsorbents, is less effective at removing. Therefore, ARUBA's AAD is likely a function of the proportions of $\mathrm{As}(\mathrm{III})$ and $\mathrm{As}(\mathrm{V})$ in the water. $\mathrm{As}(\mathrm{III})$ is absent from the aqueous arsenic solutions prepared in the laboratory.

2. Groundwater in Bangladesh contains ions that likely compete with arsenic for adsorption sites on ARUBA particles. Ions that compete with arsenic for adsorption sites on similar adsorbents include carbonate ${ }^{[27]}$, bicarbonate ${ }^{[28]}$, phosphate ${ }^{[12,28-31]}$, silicate ${ }^{[28,30-31]}$, and nitrate ${ }^{[12]}$. Interestingly, differences in concentrations of competing ions in water samples from diverse locations (i.e. Bangladesh and Cambodia) do not seem to significantly affect the linear relationship between initial arsenic concentration and AAD.

A possible way to improve ARUBA's AAD is through sequential fractionated dosing, which is a method of adding ARUBA in multiple small doses instead of one equivalent larger dose. Roberts et al. ${ }^{[31]}$ found adding multiple doses of Fe(II) to contaminated water improved As(III) removal. Exploratory experiments in the laboratory and in Bangladesh suggest that sequential fractionated dosing significantly increases ARUBA's AAD. However, further experiments are required to accurately quantify these results. 
If the arsenic concentration of a groundwater source is known and less than $1600 \mathrm{ppb}$, Figure 7 can be used to determine the number of sequential $4.0 \mathrm{~g} / \mathrm{L}$ ARUBA doses required to reduce its arsenic concentration to below the Bangladesh standard (50 ppb) or the WHO guideline (10 ppb). We illustrate the simplicity of this approach with an example. For a groundwater source with an arsenic concentration of $600 \mathrm{ppb}$, the AAD (for water stored less than one day) is approximately $0.115 \mathrm{mg} / \mathrm{g}$, which is computed using the relevant regression line in Figure 7 $\left(\mathrm{AAD}=1.91 \times 10^{-4}[\mathrm{As}]_{\text {initial }}\right)$. Adding $4.0 \mathrm{~g} / \mathrm{L}$ of ARUBA to the water will remove $\sim 460 \mathrm{ppb}$ arsenic achieving an aqueous arsenic concentration of $\sim 140 \mathrm{ppb}^{2}$ The AAD for water with an initial arsenic concentration of $\sim 140 \mathrm{ppb}$ (stored less than one day) is approximately $0.027 \mathrm{mg} / \mathrm{g}$. Adding a second $4.0 \mathrm{~g} / \mathrm{L}$ dose of ARUBA to the water (now $\sim 140 \mathrm{ppb}$ arsenic) will remove $\sim 110$ $\mathrm{ppb}$ arsenic achieving an aqueous arsenic concentration of $\sim 33 \mathrm{ppb}$, which is below the Bangladesh standard of $50 \mathrm{ppb}$. The AAD for water with an initial arsenic concentration of $\sim 33$ $\mathrm{ppb}$ (stored less than one day) is approximately $0.00638 \mathrm{mg} / \mathrm{g}$. Adding a third $4.0 \mathrm{~g} / \mathrm{L}$ dose of ARUBA to the water (now $\sim 33 \mathrm{ppb}$ arsenic) will remove $\sim 26 \mathrm{ppb}$ arsenic achieving an aqueous arsenic concentration of $\sim 8 \mathrm{ppb}$, which is below the WHO guideline of $10 \mathrm{ppb}$. Therefore, one would need to add $8.0 \mathrm{~g} / \mathrm{L}$ in two $4.0 \mathrm{~g} / \mathrm{L}$ doses to meet the Bangladesh standard and $12.0 \mathrm{~g} / \mathrm{L}$ in three $4.0 \mathrm{~g} / \mathrm{L}$ doses to meet the WHO standard.

Note that in this example we assume that the slope of the line that relates AAD to the initial arsenic concentration is constant $\left(1.91 \times 10^{-4} \mathrm{~L} / \mathrm{mg}\right)$ for each sequential ARUBA dose added. In reality, we expect that ARUBA's performance will actually improve (i.e. the slope will increase) with each sequential dose added, as explained above in the paragraph on sequential fractionated

\footnotetext{
${ }^{2}$ All calculations were done with full precision; however, only 2-3 significant figures are reported.
} 
dosing. Therefore, we believe that this methodology slightly over-estimates the amount of ARUBA required to treat contaminated groundwater.

\section{Adsorption mechanism}

Data from Bangladesh and Cambodia water samples stored less than one day (Fig. 7) were fit to three standard adsorption isotherm models (Langmuir, Freundlich, and Dubinin-Radushkevich (D-R) ${ }^{[26]}$. All of these data were derived from AAD tests conducted with the field protocol, which uses a 30-minute treatment period. Therefore, in order to fit the data to the adsorption isotherm models, we make the assumption that the arsenic concentration after the 30-minute treatment period is approximately equal to the equilibrium arsenic concentration. Table 4 and Figure 5 show that this assumption is not perfect. Instead, the arsenic concentration after the 30minute treatment period is within $25 \%$ of the equilibrium arsenic concentration.

Table 6 gives goodness-of-fit ( $\mathrm{R}^{2}$ values) and parameters for each adsorption isotherm model. All fits are similar with $\mathrm{R}^{2}$ ranging from 0.77 to 0.81 . Table 6 also includes parameters computed for each model. Note that because of the equilibrium assumption described above, the values in

Table 6 are approximate. Using the Langmuir isotherm ARUBA's adsorption capacity is $2.6 \times 10^{-6}$ $\mathrm{mol} / \mathrm{g}$ or $0.20 \mathrm{mg} / \mathrm{g}$.

\section{Removing Spent ARUBA by Coagulation and Clarifier}


As noted earlier, ARUBA is intended for use not in a packed-bed filter, but in a dispersal-andremoval process. Filters capable of removing micron-scale particles are relatively high cost and also push up operating costs. To test a lower-cost alternative, we designed and tested a $10 \mathrm{~L} / \mathrm{hr}$ conical up-flow clarifier to remove spent ARUBA from the water (details given in Mathieu ${ }^{[24]}$ ). We compared the performance of the clarifier to the performance of Whatman Grade Number 1 filter paper (particle retention of $11 \mu \mathrm{m}$ ). Two replicate experiments were performed on sample SR4 (initial arsenic concentration of $580 \pm 40 \mathrm{ppb}$ ). For each replicate, 20 liters of water were treated with $80 \mathrm{~g}$ of ARUBA $(4.0 \mathrm{~g} / \mathrm{L})$. After one hour of stirring, a small sample of the effluent was extracted before reaching the clarifier and filtered through Whatman Grade Number 1 filter paper as a control. Then, $1.24 \mathrm{~g}$ of a polyelectrolyte coagulant (dosage not optimized) was added to the remaining water and mixed for 15 minutes. Immediately afterwards the treated water was run through the clarifier ( $\sim 2$ hours) and the effluent sampled. Filtered water (the control) had an average arsenic concentration of $23 \pm 2 \mathrm{ppb}$, while the water that had been coagulated and clarified had an average arsenic concentration of $31 \pm 2 \mathrm{ppb}$. (Note that an even lower final arsenic concentration (e.g., $<10 \mathrm{ppb}$ ) can be achieved with a larger or second dose of ARUBA.) Since sample SR4 had been stored for more than two days we expect ARUBA's AAD to follow the steeper regression line in Figure $7\left(\mathrm{AAD}=2.44 \times 10^{-4}[\mathrm{As}]_{\text {initial }}\right)$. In fact, these results for the post-treatment arsenic concentration (23 and $31 \mathrm{ppb})$, given an initial arsenic concentration of $580 \mathrm{ppb}$ and an ARUBA dose of $4.0 \mathrm{~g} / \mathrm{L}$, are in the neighborhood of the expected result (14 ppb).

These results indicate that coagulation and clarification is likely a viable alternative to filtration for removing spent ARUBA from water. A coagulation and clarification system could also be used in conjunction with a mechanical filtration system. The filter would be used to remove any 
final traces of ARUBA post-coagulation/clarification. Importantly, the filter would not need frequent maintenance since the clarifier would precede it.

\section{Manganese Removal}

High levels of manganese in drinking water could have adverse health effects. The US EPA suggests reducing manganese content in drinking water to below $50 \mu \mathrm{g} / \mathrm{L} .{ }^{[32]}$ Therefore, we tested ARUBA's ability to remove manganese from Bangladesh groundwater. AAD tests were performed on water samples SR5 and SR6 and pre- and post-treatment samples were analyzed for manganese. Table 7 shows that ARUBA removes a significant portion of the manganese in Bangladesh groundwater.

\section{ARUBA Preparation Scale-up}

Commercial use of ARUBA would require the production of large quantities of ARUBA in a manufacturing facility. To assess the scalability of ARUBA preparation, a direct scale-up of the preparation protocol was used to make $200 \mathrm{~g}$ to $1 \mathrm{~kg}$ batches of ARUBA. All media performed comparably to the $100 \mathrm{~g}$ batches. Some techniques to increase the speed of ARUBA production (e.g., heat drying the media) have been explored, but results are inconclusive. See Mathieu ${ }^{[24]}$ for details.

\section{Effect of ARUBA on Other Parameters of Drinking Water Quality}


It is necessary to ensure that ARUBA's substrate, coal bottom ash, does not itself contaminate drinking water with toxic metals. The metals listed in Table 8 are RCRA listed metals ${ }^{[33]}$ and/or they have been identified as toxic or objectionable metal leachates from coal ash ${ }^{[34]}$. To determine if ARUBA-based water treatment affects drinking water quality, $2000 \mathrm{ppb}$ aqueous arsenate solution was treated with $4.0 \mathrm{~g} / \mathrm{L}$ of ARUBA and the treated water was tested for the metals listed in Table 8 . The table shows that all of the toxic metals in the treated water, with the exception of arsenic, were well below the Maximum Contaminant Levels (MCLs). Arsenic was below the Bangladesh standard of $50 \mathrm{ppb}$. A higher dosage of ARUBA would have led to a lower final arsenic concentration (e.g., below the WHO/US EPA MCL of $10 \mathrm{ppb}$ ). These results indicate that ARUBA-based water treatment does not make potable water non-potable with respect to other toxic metals.

\section{Leaching of Toxins from Spent Media}

All arsenic removal systems produce waste and ARUBA is no exception. To ensure that arsenic and other toxins will not be substantially released into the environment after disposal of spent ARUBA, we analyzed leachates from the spent media (prepared with TCLP) for the same metals as those listed in Table 8 . Table 9 shows that only arsenic and barium are released from the leachate in measurable quantities. The spent media is well within the arsenic and barium regulatory limits set by the US EPA for disposal as a non-hazardous waste. Therefore, ARUBA is harmless enough for disposal in ordinary municipal landfills per US EPA regulations. 
It is important to note that several studies have questioned the appropriateness of TCLP for assessing the leaching potential of arsenic removal wastes. ${ }^{[35-36]}$ Other than landfill disposal, spent ARUBA could be incorporated into concrete and used in road construction. Banerjee and Chakraborty ${ }^{[37]}$ found that concrete could be up to $40 \%$ arsenic-bearing sludge and still pass Indian TCLP standards.

\section{IMPLEMENTATION AND COSTS}

\section{A Possible Approach to Implementation}

Many technical studies have proposed household-based filters; however, in an extensive study Ahmad et al. ${ }^{[38]}$ found that $72 \%$ of villagers surveyed would choose a community-based technology over a household filter. This is likely because community-scale systems, especially those maintained by a trained technician, are perceived as more convenient than household filters in terms of individual time spent using and maintaining the system. Several studies have found that villagers listed convenience as the most important attribute of a water treatment system. ${ }^{\text {[38- }}$

${ }^{39]}$ In addition, several studies report household filters being abandoned because they required too much attention and maintenance. ${ }^{[38,40]}$ Based on these findings in the literature, we have developed an engineering design for a community-scale ARUBA-based water treatment center. That work is outside the scope of this paper; however, more information can be found in Mathieu ${ }^{[24]}$. Results of preliminary tests of the engineering sub-systems of the community-scale ARUBA-based water treatment center can be found in Iasmin ${ }^{[41]}$. 
One possible implementation model is a public-private partnership similar to that developed and operated by WaterHealth International (www.waterhealth.com), which provides clean drinking water to more than a million people in rural India through publicly-owned, privately-managed village-scale water treatment centers. Through a three-way partnership between a local financial institution, a local NGO, and a company responsible for constructing and maintaining the water treatment centers (all working together with the local village governments), community-scale water treatment plants could be constructed and operated in arsenic-affected villages.

Note that ARUBA has not yet undergone Environmental Technology Verification for Arsenic Mitigation (ETVAM), which is required of all arsenic remediation technologies before largescale deployment in Bangladesh.

\section{Estimated Economic Costs and Benefits}

In this section, we provide a preliminary analysis of costs (based on available cost data) associated with the scaled-up production of ARUBA. While far from a cost analysis needed for a detailed business plan, we provide some rough cost estimates and also list elements needed for a more detailed cost analysis.

Bottom ash from Indian coal fire power plants can be purchased for approximately $\$ 4$ per tonne (i.e. $1000 \mathrm{~kg}$ ) (personal communication: Girish Champhekar, 2008). We obtained estimates of bulk costs of $\$ 175$ per tonne of ferrous sulfate heptahydrate $\left(\mathrm{FeSO}_{4} \bullet 7 \mathrm{H}_{2} \mathrm{O}\right)$ and $\$ 250$ per tonne

of sodium hydroxide $(\mathrm{NaOH})$. We used these costs in the proportions needed to prepare ARUBA 
(100 g bottom ash : $157 \mathrm{~g} \mathrm{FeSO}_{4} \bullet 7 \mathrm{H}_{2} \mathrm{O}: 2 \mathrm{~g} \mathrm{NaOH}$ ) and obtain the raw materials cost of ARUBA as about $\$ 0.30$ per $\mathrm{kg}$ of ARUBA.

However, the above estimate assumes that the excess chemicals contained in the decanted liquids are discarded. We have demonstrated that the decanted (and thus recovered) quantities of $\mathrm{FeSO}_{4}$ and $\mathrm{NaOH}$ solutions can be reused for coating up to three successive batches of coal ash. This reuse, if taken into account, lowers the estimate of raw materials cost to $\sim \$ 0.08$ per $\mathrm{kg}$ of ARUBA.

Assuming groundwater with an initial arsenic concentration of $600 \mathrm{ppb}$ and a desired final arsenic concentration of less than $50 \mathrm{ppb}$ (as described previously, $8.0 \mathrm{~g} / \mathrm{L}$ of ARUBA is required), the raw materials cost of ARUBA-based water treatment per liter would be $\$ 0.00064$ per liter $(\$ 0.00008$ per g multiplied by $8.0 \mathrm{~g} / \mathrm{L})$. One can easily perform similar calculations for other initial groundwater arsenic concentrations to determine the amount of ARUBA required to treat the water (see subsection 'AAD in Bangladesh and Cambodia' for an example), and then multiplying by the raw materials cost $(\$ 0.08$ per $\mathrm{kg})$.

To estimate costs associated with ARUBA handling, transport, storage, delivery, and margins for distribution and retailing we proceeded as follows. We compared the retail prices of raw unprocessed sea salt and ground, iodized, packaged table salt in India, and attributed the difference in price to these services. We find that these services will raise the cost of ARUBA by approximately $\$ 0.10$ per $\mathrm{kg}$. 
Additional costs we have not estimated include:

1. Manufacturing costs (amortized capital equipment, labor, energy, etc.)—Costs associated with centralized ARUBA manufacturing are still a subject of research but are expected to be low due to the simple, room temperature, atmospheric pressure manufacturing processes required.

2. Cost of community-scale arsenic treatment facility (capital, O\&M, financing, etc.) - Costs are a function of the treatment center design and implementation plan. We have demonstrated that ARUBA can be removed from treated water through coagulation and clarification, potentially eliminating the use of high-cost, high-maintenance water filters capable of removing micronscale particles.

3. Waste disposal — Costs are a function of national and regional regulations for the disposal of arsenic-laden wastes.

We now turn to the benefits. For West Bengal, India, Roy ${ }^{[42]}$ estimates the welfare benefit of eliminating exposure to arsenic in drinking water at $\$ 84$ per household per year. The mean willingness to pay for recurring costs associated with an arsenic-free standpost in Bangladesh is approximately $\$ 9$ per year. ${ }^{[38]}$ These values are cited because they are important from the perspective of public policy and the economic viability of an implementation and dissemination model. Although a full cost analysis, necessary to compare ARUBA costs to these price points and benefits, is beyond the scope of this paper, the low material cost of ARUBA suggests that ARUBA-based arsenic remediation has the potential to be affordable in rural Bangladesh and India.

\section{CONCLUSIONS}


We have presented laboratory and field results of a novel adsorbent, ARUBA, that lowered arsenic concentrations in eleven samples of Bangladesh groundwater to below the Bangladesh MCL of $50 \mathrm{ppb}$. ARUBA's AAD is observed to be linearly related to the initial arsenic concentration (up to $1600 \mathrm{ppb}$ ) of groundwater from Bangladesh and Cambodia. This makes it simple to determine the amount of ARUBA needed to treat a certain water supply, if its arsenic concentration is known and within the range explored. Storing groundwater for two to three days before treatment is seen to significantly improve ARUBA's AAD for a given initial arsenic concentration. In addition to removing arsenic, ARUBA is shown to remove manganese from groundwater. Experimental results show that ARUBA does not contaminate water with other toxic elements. In addition, we find that spent ARUBA is safe enough for disposal in an ordinary landfill, per US EPA standards. We envision usage of ARUBA in community-scale water treatment centers employing a dispersal-and-removal process. We find that coagulation/clarification is capable of removing ARUBA from treated water nearly as effectively as filtration.

The public health impact of any arsenic remediation technologies depends upon its affordability to local populations. Cost estimates suggest that the costs of ARUBA-based arsenic remediation will be less than rural Bangladeshis' willingness-to-pay for arsenic-free water (specifically, arsenic-free standposts) and also less than the monetized health benefits of arsenic-free drinking water.

\section{ACKNOWLEDGEMENTS}


This work was conducted at the University of California, Berkeley and Lawrence Berkeley National Laboratory under U.S. Department of Energy Contract No. DE-AC02-05CH11231. Funders include NCIIA, and the University of California, Berkeley's Blum Center for Developing Economies and Bears Breaking Boundaries Contest. We thank the many researchers and students who built the foundation of this project: Yola Bayram, Ebere Chukwueke, Raymond Dod, Meghana Gadgil, Christie Galitsky, Lara Gundel, Mathew Jeung, Melissa Quemada, Heena Patel, Clete Reader, Mark Sippola, and Duo Wang; and members of the Berkeley Arsenic Alleviation Group: William Babbitt, Kosar Jahani, Tasnuva Khan, Nadia Madden, Shefah Qazi, and Mehmet Seflek. We gratefully acknowledge Martin Mulvihill for his technical advice. Iqbal and Kamal Quadir provided funds and support for our first trip to Bangladesh and the Khan family greatly supported our second trip. We also thank BRAC and BUET, Dhaka for their generous help and collaborative work during our fieldwork. Finally, we would like to express our deep gratitude specifically to our Bangladeshi collaborators Dr. A.B.M. Badruzzaman and Mahbuba Iasmin Ahmed at BUET.

\section{REFERENCES}

[1] Nordstrom, D.K. Worldwide occurrences of arsenic in ground water. Science 2002, 296, 2143-2144.

[2] UNICEF. Arsenic Mitigation in Bangladesh. United Nations Children's Fund, 2008. www.unicef.org/bangladesh/Arsenic.pdf (accessed: January 2010). 
[3] BGS. Arsenic contamination of groundwater in Bangladesh. WC/00/19; British Geological Survey: Keyworth, 2001. http://www.bgs.ac.uk/arsenic/bphase2/Data/NationalSurveyData.csv (accessed Apr 2009).

[4] Smith, A.H.; Lingas, E.O.; Rahman, M. Contamination of drinking-water by arsenic in Bangladesh: A Public Health Emergency. Bull. World Health Organ. 2000, 78(9), 1093-1103.

[5] Ahmed, M.F. An overview of arsenic removal technologies in Bangladesh and India. Proceedings of BUET-UNU International Workshop on Technologies for Arsenic Removal from Drinking Water, Dhaka, Bangladesh, May 5-7, 2001; 251-269.

[6] Ng, K.S.; Ujang, Z.; Le-Clech P. Arsenic removal technologies for drinking water treatment. Rev. Environ. Sci. Biotech. 2004, 3(1), 43-53.

[7] Mohan, D.; Pittman, C.U. Arsenic removal from water/wastewater using adsorbents--A critical review. J. Haz. Mat. 2007, 142(1-2), 1-53.

[8] Thirunavukkarasu, O.S.; Viraraghavan, T.; Subramanian, K.S. Arsenic removal from drinking water using iron oxide-coated sand. Water Air Soil Poll. 2003, 142(1), 95-111.

[9] Vaishya, R.C.; Gupta, S.K. Arsenic removal from groundwater by iron impregnated sand. J. Environ. Eng. ASCE 2003, 129(1), 89-92. 
[10] Su, C.; Puls, R.W. Arsenate and arsenite removal by zerovalent iron: kinetics, redox transformation, and implications for in situ groundwater remediation. Environ. Sci. Technol. 2001, 35, 1487-1492.

[11] Leupin, O.X.; Hug, S.J. Oxidation and removal of arsenic (III) from aerated groundwater by filtration through sand and zero-valent iron. Water Res. 2005, 39, 1729-1740.

[12] Tyrovola, K.; Nikolaidis, N.P.; Veranis, N.; Kallithrakas-Kontos, N.; Koulouridakis, P.E. Arsenic removal from geothermal waters with zero-valent iron-Effects of temperature, phosphate, and nitrate. Water Res. 2006, 40, 2375-2386.

[13] Rau, I.; Gonzalo, A.; Valiente, M. Arsenic(V) adsorption by immobilized iron mediation. Modeling of the adsorption process and influence of interfering anions. React. Funct. Polym. 2003, 54, 85-94.

[14] Huang, C.P.; Vane, L.M. Enhancing $\mathrm{As}^{5+}$ removal by a $\mathrm{Fe}^{2+}$-treated activated carbon. J. Water Poll. Con. F. 1989, 61(9), 1596-1603.

[15] Yavuz, C.T.; Mayo, J.T.; Yu, W.W.; Prakash, A.; Falkner, J.C.; Yean, S.; Cong, L.; Shipley, H.J.; Kan, A.; Tomson, M.; Natelson, D.; Colvin, V.L. Low-field magnetic suspension of monodisperse $\mathrm{Fe}_{3} \mathrm{O}_{4}$ nanocrystals. Science 2006, 314, 964-967. 
[16] Katsoyiannis, I.A.; Zouboulis, A.I. Removal of arsenic from contaminated water sources by sorption onto iron-oxide-coated polymeric materials. Water Res. 2002, 36(20), 5141-5155.

[17] Pal, B.N. Granular ferric hydroxide for elimination of arsenic from drinking water. Proceedings of BUET-UNU International Workshop on Technologies for Arsenic Removal from Drinking Water, Dhaka, Bangladesh, May 5-7, 2001; 59-68.

[18] Badruzzaman, M.; Westerhoff, P.; Knappe, D.R.U. Intraparticle diffusion and adsorption of arsenate onto granular ferric hydroxide (GFH). Water Res. 2004, 38(18), 4002-4012.

[19] Hussam, A.; Munir, A.K.M. A simple and effective arsenic filter based on composite iron matrix: development and deployment studies for groundwater of Bangladesh. J. Environ. Sci. Health, Part A, 2007, 42(12), 1869-1878.

[20] Gadgil, A.J.; Gundel, L.A. Galitsky, C. Arsenic Remediation of Bangladesh Drinking Water using Iron-oxide Coated Coal Ash. In Arsenic Contamination of Groundwater: Mechanism, Analysis, and Remediation; Ahuja, S., Ed.; John Wiley and Sons, 2008, 269-286.

[21] Ramakrishna, D.V.; Viraraghavan, T.; Jin, Y.C. Iron oxide coated sand for arsenic removal: Investigation of coating parameters using factorial design approach. Pract. Periodical of Haz., Toxic and Radioactive Waste Mmgt. 2006, 10(4), 198-2006. 
[22] Lai, C.H.; Lo, S.L.; Lin, C.F. Evaluating an iron-coated sand for removing copper from water. Wat. Sci. Tech. 1994. 30(9) 175-182.

[23] Lai, C.H.; Chen, C.Y.; Shih, P.H.; Hsia, T.H. Competitive adsorption of copper and lead ions on an iron-coated sand from water. Wat. Sci. Tech. 2000. 42(3-4), 149-154.

[24] Mathieu, J.L. Design of a rural water provision system to decrease arsenic exposure in Bangladesh. University of California at Berkeley Master's Project Report, 2009. http://escholarship.org/uc/item/3s68579x (accessed Jan 2010).

[25] Diamadopoulos, E.; Ioannidis, S.; Sakellaropoulous, G. As(V) removal from aqueous solutions by fly ash. Water Res. 1993, 27(12), 1773-1777.

[26] Özcan, A.; Özcan, A.S.; Gök, Ö. Adsorption kinetics and isotherms of anionic dye of reactive blue 19 from aqueous solutions onto DTMA-sepiolite. In Hazardous Materials and Wastewater: Treatment, Removal, and Analysis, Edition 1; Lewinsky, A.A., Ed.; Nova Science Publishers, 2006; 225-250.

[27] Arai, Y.; Sparks, D.L.; Davis, J.A. Effects of dissolved carbonate on arsenate adsorption and surface speciation at the hematite-water interface. Environ. Sci.a Technol. 2004, 38, 817-824.

[28] Meng, X.; Korfiatis, G.P; Bang, S.; Bang, K.W. Combined effects of anions on arsenic removal by iron hydroxides. Toxicol. Lett. 2002, 122, 103-111. 
[29] Manning, B.A.; Goldberg, S. Modeling competitive adsorption of arsenate with phosphate and molybdate on oxide minerals. Soil Sci. Soc. Am. J. 1996, 60, 121-131.

[30] Su, C.; Puls, R.W. In situ remediation of arsenic in simulated groundwater using zerovalent iron: laboratory column tests on combined effects of phosphate and silicate. Environ. Sci. Technol. 2003, 37, 2582-2587.

[31] Roberts, L.C.; Hug, S.J.; Ruettimann, T.; Billah, M.M.; Khan, A.W.; Rahman, M.T. Arsenic removal with iron(II) and iron(III) in waters with high silicate and phosphate concentrations. Environ. Sci. Technol. 2004, 38, 307-315.

[32] US EPA. Drinking Water Health Advisory for Manganese, EPA-822-R-04-003; US Environmental Protection Agency, 2004. http://www.epa.gov/OGWDW/ccl/pdfs/reg_determine1/support_cc1_magnese_dwreport.pdf (accessed Jan 2010).

[33] EHSO. Hazardous Waste Fact Sheet: TCLP: Toxicity Characteristic Leaching Procedure Characteristic Hazardous Wastes. Environmental, Health, and Safety Online, 2010. http://www.ehso.com/cssepa/TCLP\%20fact\%20sheet\%20from\%20EHSO.pdf (accessed May 2010). 
[34] Kim, A.G.; Kazonich, G.; Dahlberg, M. Relative Solubility of Cations in Class F Fly Ash. Environ. Sci. Technol. 2003, 37, 4507-4511.

[35] Badruzzaman, A.B.M. Leaching of arsenic from wastes of arsenic removal systems. Proceedings of BUET-UNU Symposium on Fate of Arsenic in the Environment, Dhaka, Bangladesh, February 5-6, 2003; 161-179.

[36] MacPhee, M.J.; Novak, J.T; Mutter, R.N.; Cornwell, D.A. Disposal of wastes resulting from arsenic removal processes. In Arsenic Exposure and Health Effects V; Chappell, W.R., Abernathy, C.O., Calderon, R.L., Thomas, D.J., Eds.; Elsevier, 2003; 483-490.

[37] Banerjee, G.; Chakraborty, R. Management of arsenic-laden water plant sludge by stabilization. Clean Technol. Envir. 2005, 7, 270-278.

[38] Ahmad, J.; Goldar, B.N.; Misra, S.; Jakariya, M. Willingness to Pay for Arsenic-Free, Safe Drinking Water in Bangladesh. World Bank Water and Sanitation Program-South Asia Report, 2003.

[39] Caldwell, B.K.; Caldwell, J.C.; Mittra, S.N.; Smith W. Searching for an optimum solution to the Bangladesh arsenic crisis. Soc. Sci. Med. 2003, 56, 2089-2096.

[40] Hoque, B.A.; Hoque, M.M.; Ahmed, T.; Islam, S.; Azad, A.K.; Ali, N.; Hossain, M.; Hossain, M.S. Demand-based water options for arsenic mitigation: an experience from rural 
Bangladesh. Public Health 2004, 118, 70-77.

[41] Iasmin, M. Assessing the effectiveness of iron-coated bottom ash in removing arsenic, manganese, and iron from groundwater. Bangladesh University of Engineering and Technology Master's Thesis, 2009.

[42] Roy, J. Economic benefits of arsenic removal from groundwater: A case study from West Bengal, India. Sci. Total Environ. 2008, 397, 1-12.

[43] US EPA. Drinking Water Contaminants--Inorganic Chemicals. U.S. Environmental Protection Agency, 2009. http://www.epa.gov/safewater/contaminants/index.html\#inorganic (accessed May 2010).

[44] WHO. Chapter 12: Chemical Fact Sheets. Guidelines for Drinking-Water Quality, 3rd Ed. Incorporating the 1st and 2nd Addenda, Vol. 1, Recommendations. World Health Organization, 2008; 296-460. http://www.who.int/entity/water_sanitation_health/dwq/GDW12rev1and2.pdf (accessed May 2010).

\section{FIGURE CAPTIONS}

Figure 1. ARUBA preparation protocol.

Figure 2. Uncoated Indian bottom ash, magnified 5,000x. 
Figure 3. ARUBA (coated Indian bottom ash), magnified 5,000x.

Figure 4. Initial and post-treatment arsenic concentrations of Bangladesh groundwater (ARUBA doses of 4.0 and $8.0 \mathrm{~g} / \mathrm{L}$ ). Error bars represent measurement error.

Figure 5. Decrease in arsenic concentration over time during treatment with ARUBA (ARUBA dose of $4.0 \mathrm{~g} / \mathrm{L}$ ). Y-axis error bars represent measurement error. X-axis error bars represent experimental error.

Figure 6. Effect of water storage duration on final arsenic concentration for (a) Sample SR2 and (b) Sample SR3. In each case, ARUBA dose is $4.0 \mathrm{~g} / \mathrm{L}$. Error bars represent measurement error.

Figure 7. $\mathrm{AAD}$ as a function of initial arsenic concentration for Bangladesh and Cambodia water samples (ARUBA dose of $4.0 \mathrm{~g} / \mathrm{L}$ ). Initial arsenic concentration errors are measurement errors. AAD errors are computed from measurement errors.

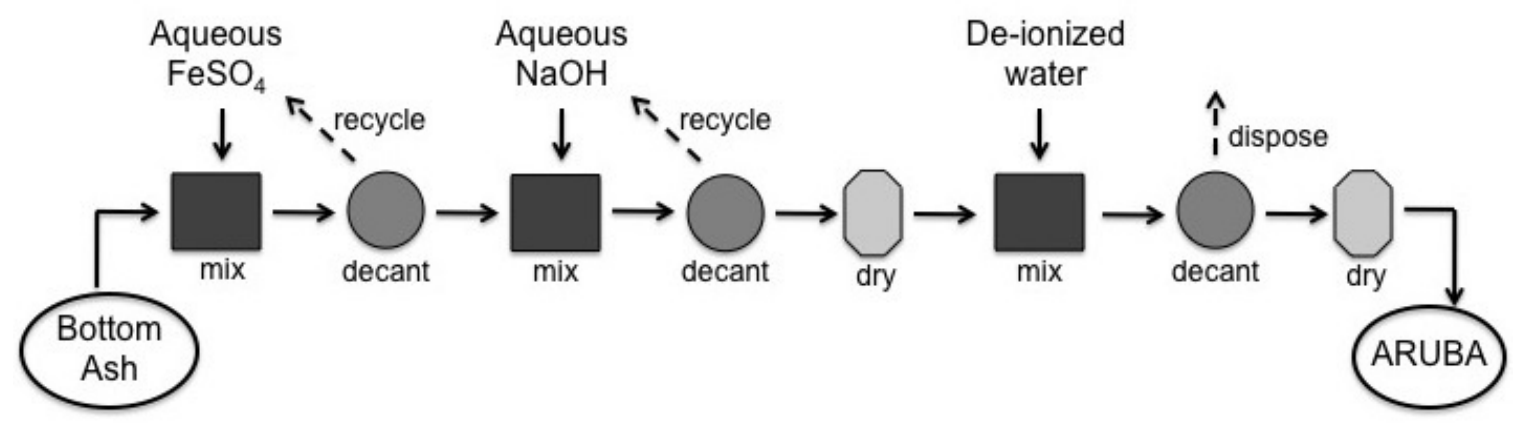

Fig. 1 


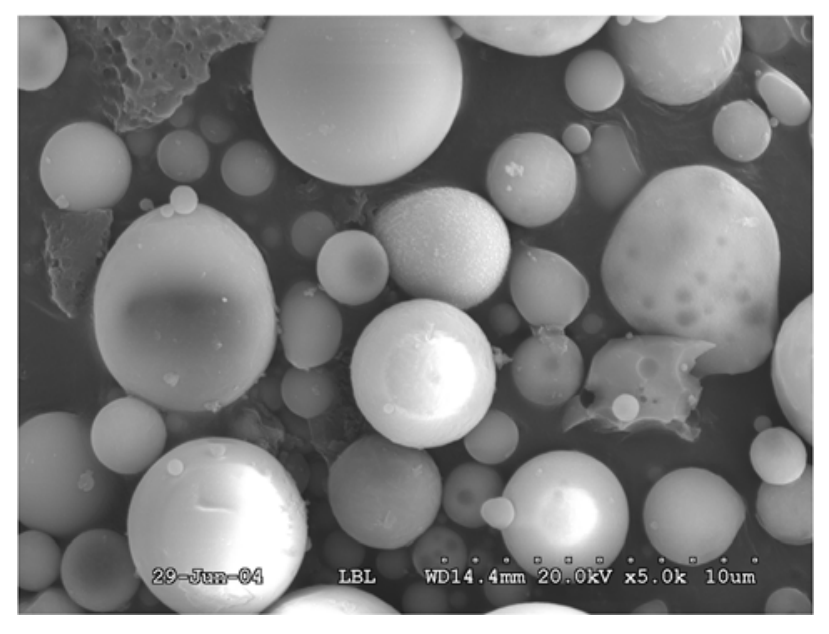

Fig. 2

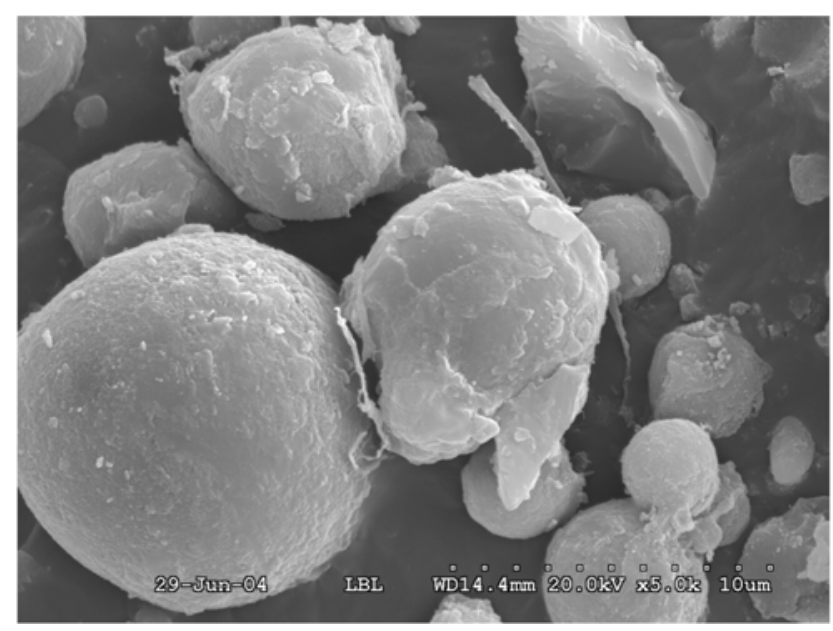

Fig. 3 


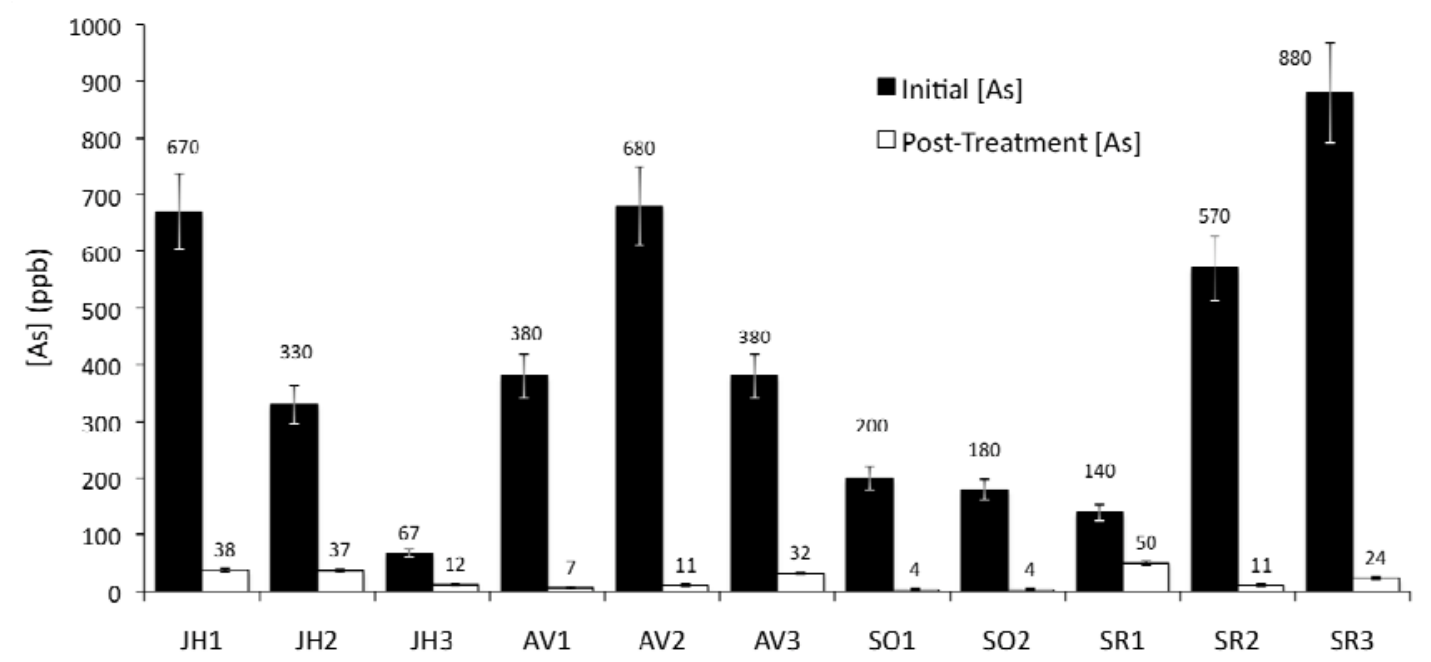

Fig. 4

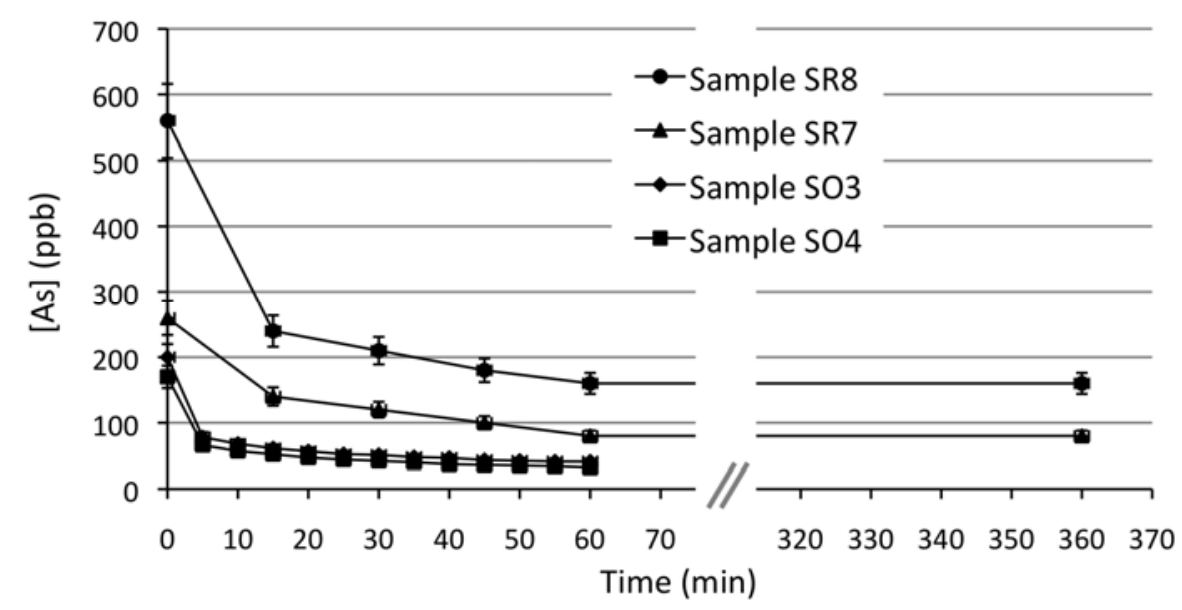

Fig. 5 


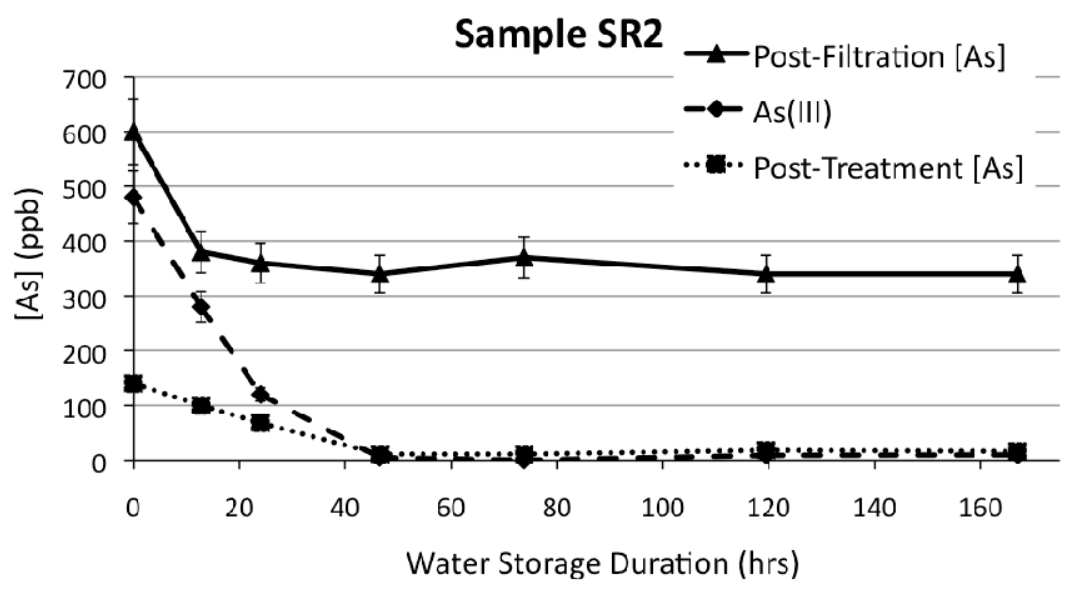

Fig. 6a

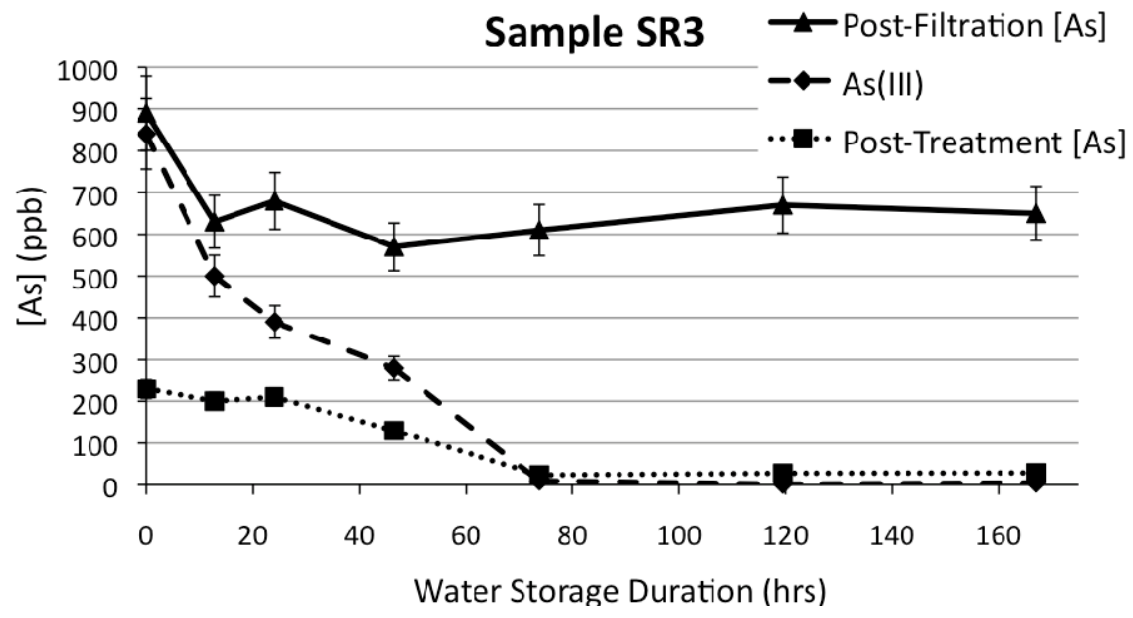

Fig. 6b 


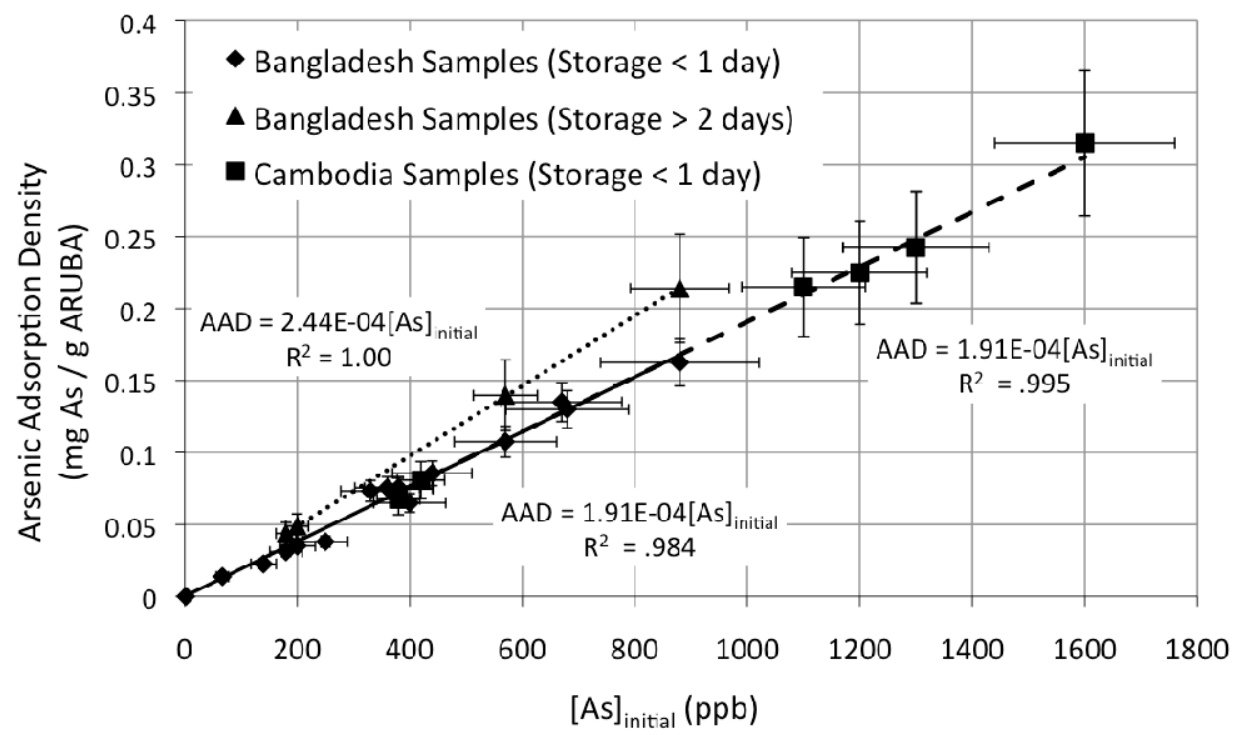

Fig. 7

Table 1. Bangladesh water samples collected to determine ARUBA's ability to remove arsenic from Bangladesh groundwater. For average parameters and concentrations of significant ions in Bangladesh groundwater by upazila (sub-district) see BGS ${ }^{[3]}$.

\begin{tabular}{cccccccc}
\hline $\begin{array}{c}\text { Sample } \\
\text { ID }\end{array}$ & Sample Date & District & Upazila & Village & $\begin{array}{c}\text { Initial } \\
\mathrm{pH}^{*}\end{array}$ & $\begin{array}{c}\text { Water } \\
\text { Storage } \\
\text { Duration } \\
\text { (hrs })\end{array}$ & $\begin{array}{c}\text { Dosage** } \\
\text { (mm/dd/yy) })\end{array}$ \\
& & & & & & & \\
\hline JH1 & $03 / 28 / 07$ & Jessore & Jhikargachha & Kamalpoura & 7.0 & 30 & 8.0 \\
JH2 & $03 / 28 / 07$ & Jessore & Jhikargachha & Yousufpur & 7.1 & 7 & 4.0 \\
JH3 & $03 / 28 / 07$ & Jessore & Jhikargachha & Patuapara & 7.3 & 4 & 4.0 \\
AV1 & $03 / 29 / 07$ & Jessore & Avaynagar & Prembug & 7.3 & 21 & 8.0 \\
AV2 & $03 / 29 / 07$ & Jessore & Avaynagar & Prembug & 7.4 & 48 & 8.0 \\
AV3 & $03 / 29 / 07$ & Jessore & Avaynagar & Prembug & 7.3 & 19 & 8.0 \\
SO1 & $07 / 02 / 07$ & Narayangani & Sonargaon & Neel Kanda & 6.9 & 77 & 4.0 \\
SO2 & $07 / 02 / 07$ & Narayangani & Sonargaon & Neel Kanda & 7.0 & 77 & 4.0 \\
SR1 & $06 / 01 / 08$ & Munshiganj & Sreenagar & Besgao & 6.9 & 11 & 4.0 \\
SR2 & $06 / 17 / 08$ & Munshiganj & Sreenagar & Besgao & 7.1 & 47 & 4.0 \\
SR3 & $06 / 17 / 08$ & Munshiganj & Sreenagar & Besgao & 7.5 & 74 & 4.0 \\
\hline
\end{tabular}

* Initial $\mathrm{pH}$ was measured at the time of sample collection. The $\mathrm{pH}$ of each sample was re-

measured directly before experiments. In all cases, the pre-experiment $\mathrm{pH}$ was 7.0-8.0.

** Dosage not optimized. 
Table 2. Bangladesh water samples collected for other experiments.

\begin{tabular}{|c|c|c|c|c|c|c|c|}
\hline $\begin{array}{l}\text { Sample } \\
\text { ID }\end{array}$ & $\begin{array}{l}\text { Sample Date } \\
(\mathrm{mm} / \mathrm{dd} / \mathrm{yy})\end{array}$ & District & Upazila & Village & $\begin{array}{c}\text { Initial } \\
\mathrm{pH}^{*}\end{array}$ & $\begin{array}{c}\text { Water Storage } \\
\text { Duration } \\
\text { (hrs) }\end{array}$ & Experiment \\
\hline $\mathrm{SO} 3$ & $07 / 03 / 07$ & Narayangani & Sonargaon & Neel Kanda & 7.0 & 7 & Time-to-90\% \\
\hline $\mathrm{SO} 4$ & 07/03/07 & Narayangani & Sonargaon & Neel Kanda & 6.9 & 8 & Time-to- $90 \%$ \\
\hline SR2 & 06/17/08 & Munshiganj & Sreenagar & Besgao & 7.1 & various** & Storage \\
\hline SR3 & $06 / 17 / 08$ & Munshiganj & Sreenagar & Besgao & 7.5 & various $* *$ & Storage \\
\hline SR4 & $06 / 27 / 08$ & Munshiganj & Sreenagar & Besgao & 7.0 & $74 / 122 * * *$ & Clarifier \\
\hline SR5 & $06 / 01 / 08$ & Munshiganj & Sreenagar & Besgao & 6.8 & 13 & Manganese \\
\hline SR6 & 06/01/08 & Munshiganj & Sreenagar & Besgao & 6.9 & 12 & Manganese \\
\hline SR7 & 06/01/08 & Munshiganj & Sreenagar & Besgao & 6.8 & 16 & Time-to- $90 \%$ \\
\hline SR8 & $06 / 01 / 08$ & Munshiganj & Sreenagar & Besgao & 6.9 & 17 & Time-to- $90 \%$ \\
\hline
\end{tabular}

* Initial $\mathrm{pH}$ was measured at the time of sample collection. The $\mathrm{pH}$ of each sample was re-

measured directly before experiments. In all cases, the pre-experiment $\mathrm{pH}$ was 6.8-8.2.

** See 'Effects of Water Storage Duration' in Results for various water storage durations. Note that SR2 and SR3 are the same samples as in Table 1.

*** SR4 was used for both the original and the repeat clarifier experiment. The original experiment started 74 hours after water collection. The repeat experiment started 122 hours after water collection.

Table 3. Comparison of the AAD of uncoated bottom ash and ARUBA (media dose of $2.0 \mathrm{~g} / \mathrm{L}$ ). For the initial and final arsenic concentrations, the reported errors are measurement errors. For the $\mathrm{AAD}$, the reported errors are computed from the measurement errors.

\begin{tabular}{lccc}
\hline & $\begin{array}{c}{[\mathrm{As}]_{\text {initial }}} \\
(\mathrm{ppb})\end{array}$ & $\begin{array}{c}{[\mathrm{As}]_{\text {final }}} \\
(\mathrm{ppb})\end{array}$ & $\begin{array}{c}\text { AAD } \\
(\mathrm{mg} \text { As } / \mathrm{g} \text { media })\end{array}$ \\
\hline Uncoated Bottom Ash & $1300 \pm 130$ & $1200 \pm 120$ & $0.050 \pm 0.007$ \\
ARUBA & $1300 \pm 130$ & $5.6 \pm 2^{*}$ & $0.65 \pm 0.24^{* *}$ \\
\hline
\end{tabular}

*The ICP-MS minimum error is $2 \mathrm{ppb}$.

**This AAD error is very large because AAD errors are computed by adding the percent errors associated with the initial and final arsenic concentrations in quadrature. Because the error on the 
final arsenic concentration is the ICP-MS minimum error ( $2 \mathrm{ppb})$, the percentage error is very large $(\sim 36 \%)$.

Table 4. Time-to- $90 \%$ for four Bangladesh water samples (ARUBA dose of $4.0 \mathrm{~g} / \mathrm{L}$ ).

\begin{tabular}{|c|c|c|c|c|}
\hline Water sample & $\begin{array}{c}{[\mathrm{As}]_{\text {initial }}} \\
(\mathrm{ppb})\end{array}$ & $\begin{array}{c}\sim[\text { As }]_{\text {equilibrium }} \\
(\mathrm{ppb})\end{array}$ & $\begin{array}{c}\sim[\mathrm{As}]_{90 \%}{ }^{*} \\
(\mathrm{ppb})\end{array}$ & $\begin{array}{l}\text { Time-to-90\% } \\
(\mathrm{min})\end{array}$ \\
\hline $\mathrm{SO} 3$ & $200 \pm 20$ & 41 & 57 & $20-25$ \\
\hline $\mathrm{SO} 4$ & $170 \pm 20$ & 32 & 46 & $20-25$ \\
\hline SR7 & $260 \pm 30$ & 80 & 98 & $45-60$ \\
\hline SR8 & $560 \pm 60$ & 160 & 200 & $30-45$ \\
\hline
\end{tabular}

* Arsenic concentration when $90 \%$ of the total amount of arsenic removed at equilibrium has been removed.

Table 5. Goodness-of-fit values ( $\mathrm{R}^{2}$ values) and kinetics model parameters for data from four water samples $\left(\mathrm{T}=26-31{ }^{\circ} \mathrm{C}\right)$ fit to three kinetics models.

\begin{tabular}{cc|ccc|ccc|ccc}
\hline \multirow{2}{*}{$\begin{array}{c}\text { Sample } \\
\text { ID }\end{array}$} & $\begin{array}{c}\text { [As] } \\
(\mathrm{ppb})\end{array}$ & \multicolumn{3}{|c|}{$\begin{array}{c}\text { First-order } \\
1 / q_{t}=1 / q_{1}+k_{l} / q_{1} t\end{array}$} & \multicolumn{3}{c|}{$\begin{array}{c}\text { Pseudo-second-order } \\
t / q_{t}=1 / k_{2} q_{2}{ }^{2}+t / q_{2}\end{array}$} & \multicolumn{3}{c}{$\begin{array}{c}\text { Intraparticle diffusion } \\
q_{t}=k_{p} t^{1 / 2}+C\end{array}$} \\
\cline { 3 - 12 } & & $\mathrm{R}^{2}$ & $\begin{array}{c}k_{l} \\
\left(\mathrm{~min}^{-1}\right)\end{array}$ & $\begin{array}{c}q_{1} \\
\left(\mathrm{~mol} \mathrm{~g}^{-1}\right)\end{array}$ & $\mathrm{R}^{2}$ & $\begin{array}{c}k_{2} \\
\left(\mathrm{~g} \mathrm{~mol}^{-1} \mathrm{~min}^{-1}\right)\end{array}$ & $\begin{array}{c}q_{2} \\
\left(\mathrm{~mol} \mathrm{~g}^{-1}\right)\end{array}$ & $\mathrm{R}^{2}$ & $\begin{array}{c}k_{p} \\
\left(\mathrm{~g} \mathrm{~mol}^{-1} \mathrm{~min}^{-1 / 2}\right)\end{array}$ & $\begin{array}{c}C \\
\left(\mathrm{~mol} \mathrm{~g}^{-1}\right)\end{array}$ \\
\hline SO4 & 170 & 0.92 & 1.78 & $4.6 \times 10^{-7}$ & 0.99 & $7.2 \times 10^{5}$ & $4.8 \times 10^{-7}$ & 0.97 & $1.95 \times 10^{-8}$ & $3.16 \times 10^{-7}$ \\
\hline SO3 & 200 & 0.92 & 1.71 & $5.3 \times 10^{-7}$ & 0.99 & $6.6 \times 10^{5}$ & $5.5 \times 10^{-7}$ & 0.96 & $2.19 \times 10^{-8}$ & $3.73 \times 10^{-7}$ \\
\hline SR7 & 260 & 0.93 & 9.04 & $6.4 \times 10^{-7}$ & 1.00 & $2.6 \times 10^{5}$ & $6.1 \times 10^{-7}$ & 0.50 & $1.02 \times 10^{-8}$ & $4.33 \times 10^{-7}$ \\
\hline SR8 & 560 & 0.93 & 4.44 & $1.4 \times 10^{-6}$ & 1.00 & $2.4 \times 10^{5}$ & $1.4 \times 10^{-6}$ & 0.46 & $1.31 \times 10^{-8}$ & $1.12 \times 10^{-6}$ \\
\hline
\end{tabular}

Table 6. Goodness-of-fit ( $\mathrm{R}^{2}$ values) and adsorption isotherm model parameters for data from 22 water samples (Bangladesh and Cambodia water samples, stored less than one day) fit to three adsorption isotherm models.

\begin{tabular}{cccc}
\hline & Langmuir & Freundlich & D-R \\
& $1 / q_{e}=1 / q_{\max }+1 / q_{\max } K_{L} C_{e}$ & $\ln q_{e}=\ln K_{F}+(1 / n) \ln C_{e}$ & $\ln q_{e}=\ln q_{m}-\beta \varepsilon^{2} *$ \\
\hline $\mathrm{R}^{2}$ & 0.77 & 0.81 & 0.80 \\
\hline Model & $q_{\max }=2.6 \times 10^{-6} \mathrm{~mol} \mathrm{~g}^{-1}$ & $n=1.1$ & $\beta=4.9 \times 10^{-9} \mathrm{~mol}^{2} \mathrm{~kJ}^{-2}$ \\
parameters & $K_{L}=4.5 \times 10^{5} \mathrm{~L} \mathrm{~mol}^{-1}$ & $K_{F}=2.1 \times 10^{-1} \mathrm{~L} \mathrm{~g}^{-1}$ & $q_{m}=4.3 \times 10^{-4} \mathrm{~mol} \mathrm{~g}^{-1}$ \\
\hline
\end{tabular}


${ }_{\varepsilon}=R T \ln \left(1+1 / C_{e}\right)$

Table 7. Initial and final (post-treatment) manganese concentrations of Bangladesh groundwater (ARUBA dose of $4.0 \mathrm{~g} / \mathrm{L}$ ).

\begin{tabular}{cccc}
\hline Water sample & $\begin{array}{c}{[\mathrm{Mn}]_{\text {initial }}} \\
(\mu \mathrm{g} / \mathrm{L})\end{array}$ & $\begin{array}{c}{[\mathrm{Mn}]_{\text {final }}} \\
(\mu \mathrm{g} / \mathrm{L})\end{array}$ & $\%$ Removal * \\
\hline SR5 & $70 \pm 7$ & $11 \pm 0.7$ & $\sim 80 \%$ \\
SR6 & $130 \pm 13$ & $14 \pm 1$ & $\sim 90 \%$ \\
\hline
\end{tabular}

*Approximate \% Removal given because value has an error of $16 \%$.

Table 8. Maximum Contaminant Levels (MCL) and element concentrations, [E], from ARUBAtreated water (ARUBA dose of $4.0 \mathrm{~g} / \mathrm{L}$ ). Measurement errors are $\pm 10 \%$. We were unable to find Bangladesh standards for any of the elements listed, with the exception of arsenic (50 ppb).

\begin{tabular}{|c|c|c|c|}
\hline & $\begin{array}{c}\text { US EPA } \\
\text { MCL }^{[43]} \\
(\mathrm{ppb})\end{array}$ & $\begin{array}{c}\mathrm{WHO} \\
\mathrm{MCL}^{[44]} \\
(\mathrm{ppb})\end{array}$ & $\begin{array}{c}{[\mathrm{E}]} \\
(\mathrm{ppb})\end{array}$ \\
\hline $\mathrm{Ag}$ & & & $<1.1$ \\
\hline As & 10 & 10 & 17 \\
\hline $\mathrm{Ba}$ & 2000 & 700 & 58 \\
\hline $\mathrm{Be}$ & 4 & & $<1.1$ \\
\hline $\mathrm{Cd}$ & 5 & 3 & $<1.1$ \\
\hline $\mathrm{Cr}$ & 100 & 50 & $<1.1$ \\
\hline $\mathrm{Cu}^{*}$ & 1300 & 2000 & 7 \\
\hline $\mathrm{Hg}$ & 2 & 6 & $<0.22$ \\
\hline $\mathrm{Mn}$ & & 400 & 14 \\
\hline Mo & & 70 & $<1.1$ \\
\hline $\mathrm{Ni}$ & & 70 & 2 \\
\hline $\mathrm{Pb}^{*}$ & 15 & 10 & $<1.1$ \\
\hline $\mathrm{Se}$ & 50 & 10 & $<1.1$ \\
\hline
\end{tabular}

Table 9. US EPA TCLP Contaminant Regulatory Levels (CRL) and element concentrations [E] from leachates exacted from spent ARUBA (loaded with $0.92 \mathrm{mg}$ As per gram ARUBA). Measurement errors are $\pm 10 \%$. 


\begin{tabular}{ccc}
\hline & $\begin{array}{c}\mathrm{CRL}^{[33]} \\
(\mathrm{ppb})\end{array}$ & $\begin{array}{c}{[\mathrm{E}]} \\
(\mathrm{ppb})\end{array}$ \\
\hline $\mathrm{Ag}$ & 5,000 & $<50$ \\
$\mathrm{As}$ & 5,000 & 170 \\
$\mathrm{Ba}$ & 100,000 & 640 \\
$\mathrm{Be}$ & & $<20$ \\
$\mathrm{Cd}$ & 1,000 & $<50$ \\
$\mathrm{Cr}$ & 5,000 & $<50$ \\
$\mathrm{Cu}$ & & $<50$ \\
$\mathrm{Hg}$ & 200 & $<1$ \\
$\mathrm{Mn}$ & & $<50$ \\
$\mathrm{Mo}$ & & $<50$ \\
$\mathrm{Ni}$ & & $<50$ \\
$\mathrm{~Pb}$ & 5,000 & $<50$ \\
$\mathrm{Se}$ & 1,000 & $<100$ \\
\hline
\end{tabular}

